\title{
References
}

Schiffer, S. 1999. The epistemic theory of vagueness. Philosophical Perspectives 13: 481-503.

Williamson, T. 1994. Vagueness. London: Routledge.

Williamson, T. 1997. Imagination, stipulation and vagueness. Philosophical Issues 8: 215-28.

Williamson, T. 1999. Schiffer on the epistemic theory of vagueness. Philosophical Perspectives 13: 505-17.

Williamson, T. 2000. Knowledge and its Limits. Oxford: Oxford University Press.

Wright, C. 2001. On Being in a quandary: relativism, vagueness, logical revisionism. Mind 110: 45-98.

Wright, C. 2003. Rosenkranz on quandary, vagueness and intuitionism. Mind 112: 465-74.

Wright, C. 2004. Vagueness: a fifth column approach. In: Liars and Heaps: New Essays on Paradox, ed. Jc. Beall and M. Glanzberg, 84-105. Oxford: Oxford University Press.

\section{Imagination and the motivational view of belief LUCY O'BRIEN}

1. The view that beliefs can be characterized solely by their motivational role promises an informative reduction of what it is for a state to be a belief state. It is therefore of import if such a view is wrong. In 'On the aim of belief' David Velleman (2000) presents an argument against such a motivational view of belief. ${ }^{1}$ On Velleman's construal of the motivational view:

All that's necessary for an attitude to qualify as a belief is that it disposes the subject to behave in ways that would promote the satisfaction of his desires if its content were true. An attitude's tendency to cause behavioural output is thus conceived as sufficient to make it a belief. (2000: 255)

It is clear that this needs a little clarification. A subject's perceptions that $p$, or desires that $p$, or questions as to whether $p$, may be such as to dispose him to form beliefs that $p$, which in their turn will dispose him to behave in ways that bring about the satisfaction of his desires, if $p$ is true. Those attitudes, therefore, dispose our subject to behave in ways that would

${ }^{1}$ His paper is a rich and fascinating one that also does much else. However, it is this aspect of the paper that is to be considered here. 
promote the satisfaction of the subject's desires if the contents were true. However, this is not sufficient to make them beliefs. It seems that the claim of the motivational view must rather be that all that's necessary for an attitude to qualify as a belief is that the attitude, by itself and relative to a fixed background of desires, disposes the subject to behave in ways that would promote the satisfaction of his desires if its content were true. ${ }^{2}$

Velleman argues that the motivational view of belief cannot be right on the grounds that attitudes, other than beliefs, can have the same motivating roles as beliefs. His overall argument involves two strands. First, he argues in favour of the following two theses:

(1) States other than belief states can be identified as states where something is regarded as true. When we assume or suppose that $p$, we regard $p$ as true. When we imagine or fancy that $p$, we regard $p$ as true.

(2) To regard $p$ as true is to represent things in a way that disposes one to behave as if $p$ were true.

It follows from these two theses that:

(3) States other than belief can dispose one to behave as if $p$ were true.

Given the claim that:

(4) A belief that $p$ disposes one to behave as if $p$ were true it seems to follow that:

(5) Beliefs and other states can share the same motivational role.

If (5) is true we clearly cannot characterize belief solely in terms of its motivational role.

The second strand of Velleman's argument is to argue directly for (5) on the basis of examples which, he claims, show that states other than beliefs can have the same motivational role as beliefs. Velleman's central example is drawn from looking at the motivational role of imagination in make-believe or pretence.

I will argue here that Velleman's central example does not serve to make convincing the claim that imaginings in make-believe have the same motivational role as beliefs. If I am right about this, we are then taken back to the general argument presented above. If we cannot produce a convinc-

${ }^{2}$ If the motivational theorist were to claim that he is operating with a notion of 'attitude' that rules out perceptions, desires, questions, or were to deny that perceptions, desires, questions can be said to have content that is true in the relevant sense, then we would no longer have a purely motivational view. The claim could no longer be that beliefs can be characterized solely in terms of their motivational role. 
ing example of an imagining and a belief sharing the same motivational roles, what are we to make of the seeming plausibility of the argument that suggests that there must be such examples? I want to suggest that the notion of 'disposing the subject to behave as if $p$ were true' does not serve to pick a unique motivational role in the sense required by the motivational view. This results in the argument not going through. In particular, the move from (4) to (5) will be illegitimate.

2. I want now to consider the cases that, Velleman claims, show that imaginings and beliefs can be on a par in their motivating roles. It seems to me that, in fact, the motivational role of imaginations will have to piggy-back on the motivational role of beliefs, because the power of beliefs to aid in bringing about bodily action depends upon their operating against a background of an embodied subject who knows as a standing condition which body to move, and how, when she tries to act.

Let us consider Velleman's central example. Velleman asks us to consider the example of child's play, in which imagining disposes the child to pretend. In particular he considers the case of a child pretending that he is an elephant. Velleman argues that such cases of pretence are cases in which imagining being an elephant disposes the child to behave as if he were an elephant:

The child's method is to imagine being an elephant - weighing a ton, walking on stumpy legs carrying floppy ears - and then to wait and see how he is disposed to behave. (2000: 257)

Velleman argues very convincingly, and importantly, that in pretending to be an elephant, the child does not intend to simulate elephant appearances: to act in ways which will fool others in to thinking that he is really an elephant. Rather what he does is imagine being an elephant, imagine having big heavy elephant feet and so on. He then acts on the basis of such imaginings. I agree with Velleman that trying to create elephant appearances is not what a pretending subject does. I also agree that the child acts on the basis of his imaginings. However, if the example is going to do the work required of it, it needs to be shown not just that the child's imaginings can motivate action, but that they can motivate action in just the way that beliefs do in the normal case. Velleman claims that this is just what we have to claim if we are to provide an account on which the child is taken as properly engaged in the actions that constitute his pretence, and avoid an account that takes the child's play as depressingly calculating and disengaged.

The first thing to note is that, in pretending, the child seems to be motivated not just by imagining being an elephant. A child can perfectly well be day-dreaming, imagining being an elephant wandering through 
the plains of Africa, without thereby pretending that he is an elephant. In pretending the subject is also motivated to act out his imaginings. It is plausible to claim that the child's pretending is motivated by a desire to act out his imaginings. That desire might be motivated by a number of other desires: his desire to be an elephant, his desire to play the elephant game with his friends, or perhaps by the desire that he keeps track of, and so aids, his imaginings. Claiming this motivation for the child's behaviour does require that he in some sense operates with an awareness of a distinction between that which is real and that which is imagined. But, it does not seem that acknowledging these elements of a child's understanding and motivation gives us a picture of the child's activity that is depressing or makes it seem disengaged. Whilst the child operates with a real-world desire, the desire leads to behaviour which is imagination led: it is a desire to be governed by the contents of his imaginings rather than his beliefs. Velleman may not disagree with any of this.

However, and here we prima facie diverge from Velleman, in order for the child to be motivated to act and so satisfy his desire of acting out his imaginings, it must be that he does more than imagine. Prior to accomplishing his aim of acting out his imaginations he needs to complete the task of draping the contents of his imaginings over the real world that he knowingly inhabits and knows how to act in. Consider the child imagining (from a first person perspective) some elephant desiring to drink from a pail of water and imagining (from a first person perspective) the same elephant believing that hanging its trunk over a pail will enable it to drink. Merely imagining these will do nothing to cause the child to hang his arm over a chair. The child also needs, besides desiring to act out his imaginings, to do something to connect the content of his imagining to the world that he can act in and needs beliefs about that world. He needs things he can act with, and on, to go proxy for those things that he would act with, and on, were his imaginings real. Now, as he can only act with his own body, and only on those objects in the space around him, he needs to assign to his arm the value of being a trunk and to the chair the value of being a pail. Also, he needs to believe that he has an arm, that there is a chair in front of him, that the chair is within reach and so on.

If what I have said is right, then imaginings that $p$, in such cases as the child pretending to be an elephant, cannot be said to play the same motivational role as the belief that $p$. The attitude of imagining that $p, b y$ itself and relative to a fixed background of desires, does not dispose the subject to behave in ways that would promote the satisfaction of his desires if its content were true. Further, it seems to be a quite general point that any 'regarding as true' states which are not beliefs, will require this kind of connection to the subject's beliefs about his actual world if they are to result in action. Thus, it seems a quite general point that such merely 
'regarding as true' states will play a different motivating role from belief states.

Now, Velleman is likely to reply at this point that there is a misunderstanding: that it was not such imaginings as imagining 'being an elephant who desires to drink from a pail of water', that were claimed to be able to motivate in just the way that beliefs are. It was rather the imaginings which connect between the imagined world and the real one that were candidates for attitudes with the same motivational role as beliefs. It was imaginings such as my imagining of my (LOB's) arm that it is my trunk (as opposed to my imagining - from a first person perspective - having a trunk), my imagining of me (LOB) that I am an elephant (as opposed to my imagining being an elephant), and my imagining of that chair, that it is a pail (as opposed to imagining being in front of a pail). It is these imaginings conjoined only with desire that can dispose the subject to act as beliefs do. However, if this is the position, a number of problems now emerge.

First, it is claimed that regarding $p$ as true, whether in belief or imagination, can play the same motivational role. However, it is now hard to see what belief my imagining that I (LOB) am an elephant can be compared to in order to test for sameness of motivational role. If I somehow could come to believe - rather than have a delusion - that I (LOB) am an elephant then, it would seem to have a very different motivational role to the corresponding imaginings. I would probably be trying to find ways to resign from my job, break it to my family, buy a new bed and so on. I feel motivated to do none of these things when I imagine I am an elephant. And the same seems to be true of the child.

Second, but connected to the first point, it seems problematic to take the imaginings in the make-believe case as attitudes of regarding-as-true, in the sense that beliefs are taken to be regardings-as-true. Velleman assumes that a belief necessarily involves regarding a proposition as true. But, do I regard as true the propositions that 'my arm is my trunk', that 'I am an elephant', or that 'the chair is a pail'? I could only regard these as true if I were prepared to regard it as true that something can be both an arm and a trunk etc. But it seems problematic to claim that I can even merely regard as true that something be both an arm and a trunk. It seems more natural to take such imaginings as attitudes, which like some perceptions, can be directed at objects - the attitude of regarding my arm as a trunk, myself as an elephant etc. Imagining my arm to be a trunk is more like seeing the cloud as a camel, the duck as a rabbit, than like believing that my arm is a trunk. However, if this is the right thing to say, then the imaginings that have the power to motivate cannot be regarded as attitudes of regarding-as-true in the sense that beliefs are. If the imaginings that motivate in the child's make-believe are not regarding-as-true 
states, then the example cannot serve to fortify Velleman's claim that belief and other regarding-as-true states can share motivational roles. In fact, if it is right to say that such imaginings as 'my arm is a trunk' do not involve the subject standing in relation to a proposition that he regards as true, we are going to have trouble even making sense of the claim that it is an attitude that 'disposes the subject to behave in ways that would promote the satisfaction of his desires if its content were true'. We are going to find it hard to say anything about what would happen if its content were true, given that its content cannot be true.

Third, suppose we accept that the child's imaginings (that he is an elephant etc.) are regarding-as true states with a propositional content whose truth conditions we understand. We still have to acknowledge that his imaginings play a motivational role only relative to the child's beliefs about himself and his world. Such imaginings will not lead to action by themselves, relative to certain desires. They will lead to action only given that the child believes that he has an arm, that there is a chair in front of him, and so on. Given that the child's imaginings are dependent in this way for their motivating power on the child's beliefs it is implausible to suppose that they can have the same motivational roles.

3. Let me assume that in $\$ 2$ we saw good reason to doubt that imaginings and beliefs have the same motivational role. Rather than the motivational role of imaginings and beliefs being on a par, the motivational role of imaginings depends upon the motivating role of beliefs. What, then, are we to make of the general argument presented above?

The discussion of Velleman's case of child's play has I hope brought out the fact that rather different kinds of motivational role can be indicated by the locution 'being disposed to behave as if $p$ were true'. One can, roughly, be 'disposed to behave as if $p$ were true' if one 'is disposed to behave, as one would, when one takes $p$ to be actually true or, distinctly, 'if one is disposed to behave merely as if $p$ were true, when one does not take $p$ to be actually true'. What consequences does this have for Velleman's more general argument? It now seems that the transition from (4) to $(5)$ is illegitimate. We can no longer move from a claim about dispositions to behave as if $p$ were true to a claim about motivational role. If we were to try to tighten the notion of 'behaving as if $p$ were true' so that it picks out only one motivational role, then the argument barely gets off the ground. If we read 'being disposed to behave as if $p$ were true' as 'is disposed to behave, as one would, when one takes $p$ to be actually true' then (2) appears to be false. Imaginings and assumings will constitute a counter-example. If we rather read 'being disposed to behave as if $p$ were true' as if one is disposed to behave merely as if $p$ were true, when one does not take $p$ to be actually true', then both (2) and (4) appear to be 
false. (2) will be false as long as belief counts as a state in which one 'regards $p$ as true' and it will not be plausible to claim (4), that beliefs dispose the subject to behave merely as if $p$ were true.

Velleman's discussion succeeds brilliantly in his main aim of showing us that imaginations can indeed play a critical role in motivating us to act. However, he does not, I think, show that they can play the same motivating role as beliefs, and so does not undermine a motivational view of belief.

Does this mean that we should accept the motivational view? I think not. If anything, I think it turns out that Velleman's error is not that he is too critical of the motivational theorist. Rather he is not critical enough.

The argument above in fact counts against even a motivational thesis of 'regarding as true' states. Given the distinction between motivational roles we have made, if we continue to accept the motivational view of 'regarding as true', encapsulated in (2), we have to choose to accept either:

$\left(2^{\prime}\right)$ To regard $p$ as true is to represent things in a way that disposes one to behave, as one would, when one takes $p$ to be actually true.

Or

$\left(2^{\prime \prime}\right)$ To regard $p$ as true is to represent things in a way that disposes one to behave merely as if $p$ were true, when one does not take $p$ to be actually true. ${ }^{3}$

If we accept $\left(2^{\prime}\right)$ we can no longer take imaginings, assumptions etc. to be 'regarding as true' states. If we accept (2") we can no longer take belief to be a case of 'regarding as true'. If we retain the understanding of regarding-as-true states that we started with, we are going to have to give up the motivational view of them. However, the motivational theorist about belief may still claim that beliefs are a class of regarding-as-true states which can be characterized solely by their motivational role. To regard $p$ as true in a way that constitutes believing $p$, it might be said, is just to represent things in a way that disposes one to behave as one would, when one takes $p$ to be actually true. Such a claim can, however, only be sustained if all representational states that dispose a subject to behave as they would when they to take $p$ to be actually true, are in fact states where the subject regards $p$ as being actually true, viz. belief states. Can we rule out the possibility of a representation with the same motivational role as a belief but for which we cannot say that it constitutes a case of the subject

${ }^{3}$ In fact, there is good reason to doubt that 'to be disposed to behave as if $p$ were true' will pick up any particular set of dispositions, and therefore any particular motivational role. 
regarding anything as true? Might there not be representations that promote the satisfaction of the subject's desires just if their content is true but which are more primitive than beliefs?

This is not the place to answer these questions. Nevertheless, it seems that to regard something as true, no less than to believe it, is to adopt an attitude which makes us responsive to norms of rationality. Being in a representational state with the right motivational powers does not obviously imply being subject in the same way to the relevant norms, and so does not obviously imply being in a state of regarding as true. In assessing the motivational theory of belief, we might do better to consider, not whether the motivational theory fails to distinguish one kind of regarding-as-true attitude from another, but rather whether it fails to rule out the possibility of states which share the motivational role of beliefs, but which cannot be considered even as attitudes in which the subject regards something as true. ${ }^{4}$

University College London

London WC1E 6BT, UK

l.o’brien@ucl.ac.uk

\section{Reference}

Velleman, J. D. 2000. On the aim of belief. In The Possibility of Practical Reason, 244-81. Oxford: Oxford University Press.

4 Thanks to Tim Crane for being the initial spur to this discussion, by inviting me to respond to Velleman at the conference Aiming at Truth: Belief Desire and the Attitudes, in London, November 1999. Thanks also to Michael Clark, Mike Martin and Mark Sacks for very helpful discussion and comments.

\section{An alleged problem for possible worlds semantics}

\section{GeOrge F. SCHumm}

Yannis Stephanou (2000) has conjured up a seductive argument against the basic modal principle

(S) [It is possible that $p$ ] iff [there is a possible world $w$ such that, at $w, p]$,

when the existential quantifier is understood objectually. He thus joins a number of critics who have claimed that there are cardinality problems facing substantive accounts of possible worlds. Certainly, if (S) has to go, 